\title{
PRÁTICAS DE EDUCAÇÃO AMBIENTAL NAS AULAS DE GEOGRAFIA DO ENSINO MÉDIO: RECICLANDO VELHOS HÁBITOS
}

\author{
Welington Inacio Silva ${ }^{1}$ \\ Jully Gabriela Retzlaf de Oliveira ${ }^{2}$
}

Resumo: Diante do problemático quadro ambiental planetário, faz-se necessário a realização da Educação Ambiental nas escolas, sendo esta o processo que consiste em proporcionar às pessoas uma compreensão crítica e global do ambiente. Este trabalho teve por objetivo discutir a Educação Ambiental e seu desenvolvimento nas aulas de Geografia, em específico apresentar práticas de Educação Ambiental realizadas nas aulas de Geografia do Ensino Médio. Metodologicamente, este artigo foi estruturado da seguinte forma: 1) análise e discussão teórica de autores e literaturas especializadas no assunto; 2) seleção de práticas de ensino de Educação Ambiental; 3) aplicação das práticas; e 4) apresentação e análise das práticas de ensino. A abordagem da Educação Ambiental nas aulas de Geografia compreendeu aulas expositivas e oficinas para trabalhar a Educação Ambiental, sendo elas: 1) Puff com caixa de leite; 2) Puff com pneu; 3) Artesanato com matérias recicláveis; e 4) Jardim suspenso com pallet, garrafa pet e pneu.

Palavras-chave: Geografia Escolar; Consciência Ambiental; Reciclagem.

\footnotetext{
1 Universidade Estadual do Norte do Paraná. Email: welington02 inacio@hotmail.com.

2 Universidade Estadual do Norte do Paraná. Email: jullygeo@yahoo.com.br.
} 


\section{Introdução}

Diante do quadro ambiental planetário, faz-se necessário que sejam realizadas práticas educativas que provoquem mudanças nos indivíduos, tanto em âmbito local quanto nos contextos regional e mundial. Assim sendo, a Educação Ambiental no ambiente escolar traz consigo a finalidade de possibilitar melhorias à sociedade sobre os modos de como agir em relação ao meio ambiente, sendo tal agir consciente (NARCIZO, 2009).

Desta forma, é necessário que haja indivíduos ambientalmente educados, sendo capazes de observar, analisar e interpretar as problemáticas ambientais contemporâneas. Ademais, tais indivíduos devem ainda ser capazes de propor ações e soluções para modificar situações, sendo então, a Educação Ambiental, dentro do espaço escolar, de extrema importância para alcançar a sustentabilidade ambiental, além da socialização dos conteúdos e temáticas ambientais (BARROS; SILVA, 2009).

Por fim, a Educação Ambiental possibilita uma práxis educativa e principalmente social, cuja finalidade volta-se à construção de valores, habilidades, conceitos e atitudes que permitam o entendimento da realidade ambiental (LOUREIRO, 2002).

Trabalhar a Educação Ambiental nas aulas de Geografia, especificamente através de práticas de ensino, torna-se interessante e necessário, pois a Geografia permite trabalhar ativamente questões ambientais, atitudes e ações para a preservação da natureza, partindo da abordagem de temas socioambientais, que possam potencializar a formação de sujeitos críticos e atuantes na realidade vivida.

Metodologicamente, este artigo trata-se de uma pesquisa bibliográfica sobre Educação Ambiental com apresentação e análise de práticas de Educação Ambiental nas aulas de Geografia, estruturado da seguinte maneira: 1) análise e discussão teórica de autores e literaturas especializadas no assunto; 2) seleção de práticas de ensino de Educação Ambiental para serem aplicadas nas aulas de Geografia; 3) aplicação das práticas de ensino nas aulas de Geografia do Ensino Médio em uma escola pública localizada no município de Cornélio Procópio (PR); e 4) apresentação e análise das práticas de ensino desenvolvidas.

Portanto, o objetivo deste trabalho foi discutir a Educação Ambiental e seu desenvolvimento nas aulas de Geografia, com apresentações de práticas de Educação Ambiental realizadas nas aulas de Geografia do Ensino Médio, abordando a reciclagem de resíduos sólidos e a confecção de artesanato como forma de promover a reutilização de tais materiais.

\section{Considerações Gerais sobre a Educação Ambiental}

$\mathrm{Na}$ atualidade, como o homem está exercendo relações de poder sobre Vivendo "o homem contemporâneo profundas dicotomias. Dificilmente se 
considera um elemento da natureza, mas como um ser à parte observador e/ou explorador da mesma" (REIGOTA, 2001, p.11). Em decorrência do exposto, a natureza sofre as mais variadas modificações em sua estrutura natural.

Acrescenta-se a isso que o modelo de produção capitalista vigente, cujo modo de desenvolvimento está pautado no consumismo em massa, não respeita os "limites" da natureza para poder desenvolver livremente, sua produção (DAMIANI, 2012, p.17). Desta maneira o utilitarismo dos recursos naturais ganha uma nova visão.

De acordo, com Reigota:

(...) o problema ambiental não está na quantidade de pessoas que existe no planeta e que necessita consumir cada vez mais os recursos naturais para se alimentar, vestir e morar. É necessário entender que o problema está no excessivo consumo desses recursos por uma pequena parcela da humanidade e no desperdício e produção de artigos inúteis e nefastos à qualidade de vida (REIGOTA, 2001, p.9).

Dentro desse contexto, surge a necessidade de se pensar em uma educação capaz de modificar o quadro atual. Com efeito, nessa educação deve ser inserida juntamente a formação de uma consciência ambiental (PENTEADO, 2001). Ao contrário de outras espécies que estabelecem naturalmente limites para seu desenvolvimento, vivendo de forma equilibrada com o meio natural, a espécie humana, encontra dificuldade ao estabelecer esses limites de crescimento/desenvolvimento, uma vez que acredita ser necessário consumir e produzir cada vez mais para considerar-se desenvolvida.

O "bicho homem" altera deliberadamente a si e ao seu meio ambiente. Faz isso, coletivamente através do trabalho que organiza as relações sociais que estabelece. As organizações do trabalho.

Ainda é preciso considerar que todos os elementos componentes do meio ambiente-minerais, animais e vegetais mantém estreitas relações entre si, de tal maneira que uma alteração em quaisquer um deles reflete-se nos demais. Diante disso, e sendo o homem um ser essencialmente criador, sua capacidade de alteração ambiental é muito ampla (PENTEADO, 2001, p.72).

A necessidade de sensibilizar a humanidade é evidente na atualidade, portanto é imprescindível que ocorra uma sensibilização voltada à consciência ambiental, pois o fato de o homem ser criador de culturas interfere sobre a sua própria espécie. Ao ser sensibilizada, a espécie humana tomará a consciência da necessidade de conservar o meio ambiente, pois o ambiente estável e 
saudável no presente torna-se a garantia da estabilidade para as próximas gerações das mais variadas espécimes de animais, minerais, vegetais e, principalmente, da espécie humana. Cabe ao homem conservar e manter o seu espaço na atualidade, para que o mesmo possa existir no futuro. E esta sensibilização deve partir de todos, pois “(...) todos temos que ver o meio ambiente, ninguém sozinho consegue resolver nada" (PENTEADO, 2001, p.95). Assim faz-se necessária a colaboração de todos, compreendendo indivíduos das esferas públicas e privadas, ricos e pobres, homens e mulheres, adultos e crianças. Independente de idade, gênero ou classe social, todos os grupos estão inseridos no meio ambiente, e a alteração deste resultará em consequências graves a todos.

Faz-se necessário a modificação do modo de vida humana, baseado no consumo em massa, consumo este movimentado principalmente pelo capitalismo, que faz com que cada vez mais se consuma mais e mais. $O$ consumo está ligado à sensação de desenvolvimento e prosperidade. Dentro desse contexto, surgiram ao longo do século passado diversos encontros e conferências para discutir os problemas ambientais planetários.

Dias (2000) coloca que as alterações ambientais globais agravam a crise ambiental, produzindo mudanças indesejáveis (alterações climáticas, destruição de habitats, desflorestamento, perda de solo, extinção de espécies e diversidade de ecossistemas, poluição, escassez de água potável, erosão cultural e outras).

Estas alterações estão ligadas ao modo de produção capitalista que, ao realizar atividades prejudiciais aos meios naturais, polui rios, derruba florestas, muda todos os aspectos naturais de toda a biodiversidade. Tal modificação do ecossistema iniciou-se no momento em que o meio ambiente foi visto como um grande "supermercado", detentor de recursos inesgotáveis, mas "às vésperas do século XXI as questões sobre o meio ambiente se apresentam como um dos problemas urgentes a serem resolvidos nos novos tempos" (...) (PENTEADO, 2001, p.9).

Os problemas ambientais, na década de 1960, mostravam a irracionalidade do modelo econômico, iniciado após as grandes revoluções industriais. Entretanto, neste momento, mesmo com todas as problemáticas ambientais no âmbito mundial, não se falava em Educação Ambiental. O termo surge pela primeira vez somente na segunda metade da década de 60, especificamente no ano de 1965, na Inglaterra, onde a expressão surge com as recomendações necessárias para a prática da consciência ambiental, além da consciência social (DIAS, 2000).

Para Guimarães (2010 p.23),

na poética da EA, a atenção à degradação ambiental muitas vezes deixa escapar a injustiça social. Por isso é preciso reivindicar a consciência reflexiva de que toda miséria humana está intrinsecamente relacionada com os impactos ambientais. 
Após o uso do termo Educação ambiental pela primeira vez em 1965, no ano de 1968, diversos cientistas encontram-se na cidade de Roma para poder discutir sobre as reservas naturais não renováveis, o consumo das mesmas, além do crescimento populacional no âmbito mundial até meados do século XXI. Tal evento ficou conhecido como Clube de Roma (REIGOTA, 2001). A extrema necessidade de buscar meios e métodos capazes de desenvolver uma conscientização ambiental ficou visível, pois neste momento os problemas ambientais ganharam conotação mundial.

No ano de 1972 ocorreu a 1ํㅡㄹ Conferência de Estocolmo, conferência da Organização das Nações Unidas - ONU sobre o Ambiente Humano entre 5 a 16 de junho, na Suécia, com representantes de 113 países. A conferência gerou a Declaração sobre o Ambiente Humano, atendendo à necessidade de estabelecer uma visão global e princípios comuns que serviriam de inspiração e orientação à humanidade para a preservação e melhoria do ambiente humano. Oferece orientação aos governos, estabelece Planos de Ação Mundial e, em particular, recomenda que seja estabelecido um programa internacional de Educação Ambiental, visando educar o cidadão comum para que este maneje e controle seu ambiente (DIAS, 2000).

Foi através da Conferência de Estocolmo (1972) que a Educação Ambiental passou a ser considerada como um campo de ação que poderia ser exercido sobre as áreas pedagógicas, haja vista que "a escola é, sem sombra de dúvida, o local ideal para se promover este processo" (PENTEADO, 2001, p.16). Além das práticas pedagógicas, a Educação Ambiental no ambiente escolar permite a formação de uma consciência ambiental, no pleno exercício da cidadania.

A esse respeito, Penteado (2001) destaca que o desenvolvimento da cidadania e a formação da consciência ambiental têm na escola um local adequado para sua realização através de um ensino ativo e participativo. Também, a Educação Ambiental "deve ser entendida como educação política, no sentido de que ela reivindica e prepara os cidadãos para exigir justiça social, cidadania nacional e planetária, autogestão e ética nas relações sociais e com a natureza" (REIGOTA, 2001, p.10).

Em 1975, em Belgrado na lugoslávia, ocorreu o Encontro Internacional sobre Educação Ambiental, promovido pela UNESCO, contando com a participação de especialistas de 65 países. O encontro gerou orientações para se promover um Programa Internacional de Educação Ambiental. Houve também a criação da "Carta de Belgrado", um documento histórico na evolução do ambientalismo, no qual é expressa a importância do exercício de uma nova ética global (DIAS, 2000).

Assim, após dois anos da realização do Encontro Internacional sobre Educação Ambiental, em Belgrado - lugoslávia, em 1977, foi realizada a Conferência Intergovernamental sobre Educação Ambiental, em Tbilisi, URSS, organizada pela UNESCO, com a colaboração do Programa das Nações Unidas para o Meio Ambiente - PNUMA. Nesta conferência, definiram-se

revista brasileira educação ambiental 
estratégias pertinentes para a conservação ambiental, tanto em nível nacional como no internacional, já que a Conferência em Tbilisi foi o ponto culminante da primeira fase do Programa Internacional de Educação Ambiental, que se iniciou em 1975 na Conferência de Belgrado (DIAS, 2000).

A importância de fazer crescer a conscientização ambiental, foi a base para que fossem realizados encontros e conferências em escalas regional, nacional, continental e mundial. $O$ avanço das conferências deu ênfase às relações sociedade-natureza e podem ser destacadas no ambiente escolar, desenvolvendo e capacitando o cidadão com senso crítico, além de promover a aprendizagem de habilidades que possam resolver problemas ambientais (DIAS, 2000). Neste sentido, na formação de uma consciência ambiental, o trabalho a ser desenvolvido pela educação, através de professores, as aulas são o espaço ideal de trabalho com os conhecimentos e onde se desencadeiam experiências e vivencias formadoras de consciência mais vigorosas (PENTEADO, 2001, p.16).

Entretanto "é prudente levarmos em conta que muitos professores nunca tiveram oportunidade de estudar os referenciais teóricos da $E A$, não conhecem sua história, seus objetivos e princípios" (GUIMARÃES, 2010 p.88). Para entender a Educação Ambiental, deve saber definir o que é meio ambiente. $\mathrm{O}$ autor coloca que o meio ambiente não é apenas o somatório das partes que o compõem, mas também a interação entre essas partes em interrelação com todos, sendo a unidade que contém a diversidade em suas relações antagônicas e complementares de forma muitas vezes simultânea.

Portanto, não se pode deixar de lado as mudanças da realidade socioambiental. Cabe a postura dos indivíduos realizar transformações positivas sobre o meio ambiente, e a EA é importante fonte para a realização dessas transformações. Não obstante se deve levar em conta que somente a Educação Ambiental, não fará grandes mudanças: esta necessita andar junto com as políticas públicas, além de ser necessário o comprometimento de pessoas e instituições para a aplicação da conscientização ambiental.

Dessa forma, a Educação Ambiental deve estar presente em todos os espaços, pois o meio ambiente é onde ocorrem as relações dinâmicas, com constantes interações entres os aspectos naturais e sociais. Em vista disso, a Educação Ambiental tem como função proporcionar aos indivíduos a capacidade de participar ativamente nas resoluções dos problemas ambientais, sejam em escala local, regional, nacional e até mundial (REIGOTA, 2001).

Assim sendo, a Educação Ambiental pode ser definida como o processo que consiste em proporcionar às pessoas uma compreensão crítica e global do ambiente para desenvolver atitudes e valores que permitam uma posição consciente e participativa na busca por soluções dos problemas ambientais, que atingem nosso planeta, desenvolvendo conhecimentos, habilidades, motivações e compreensão sobres tais questões e problemas que atingem a todos (DIAS, 2000). 
É de fundamental importância que a Educação Ambiental esteja em todos os espaços que eduque em todas as modalidades de ensino, seja na educação infantil, até no ensino superior, pois para ela não há limites de idade (REIGOTA, 2001), devendo estar presente sempre para que haja mudanças significativas na mentalidade dos indivíduos, no sentido de que mudem a visão de consumo proposta pelo capitalismo moderno, que se baseia na relação de desejos de consumo e não na real necessidade. Assim, a Educação Ambiental é de extrema importância no ambiente de ensino. No Brasil, a Lei oㅜ 9.795 de 27 de abril de 1999, em seu Cap. I. art. $2^{\circ}$ determina que "a educação ambiental é um componente essencial e permanente da educação nacional, devendo estar presente, de forma articulada, em todos os níveis e modalidades do processo educativo, em caráter formal e não-formal' (BRASIL, 1999).

A Educação Ambiental tem seis objetivos principais, sendo ele: conscientização; conhecimento; comportamento; competência; capacidade de avaliação; e a participação. A conscientização se resume em levar aos indivíduos e aos grupos associados o entendimento da consciência do meio ambiente global, além de proporcionar a estes noção dos problemas conexos, para que se demonstrem, assim, sensíveis aos mesmos. O conhecimento é saber e perceber os problemas ambientais, proporcionando, assim uma responsabilidade crítica do ser humano. O comportamento busca adquirir o sentido dos valores sociais, contribuindo para a proteção e qualidade ambiental. Já a competência refere-se a proporcionar aos indivíduos o alcance do êxito necessário à soluções dos problemas ambientais. A capacidade de avaliação diz respeito ao processo capaz de avaliar as medidas e programas que estejam relacionados ao meio ambiente, sejam em funções de fatores de ordem educativa, econômica, ecológica, política e até social-estética. E, por fim, e não menos importante, a participação, que faz com que os indivíduos percebam sua responsabilidade na busca por soluções dos problemas ambientais, demonstrando a necessidade de ação imediata sobre o meio ambiente, agindo ativamente em favor da qualidade ambiental, sua conservação e preservação (REIGOTA, 2001).

O ser humano deve estar apto a agir conscientemente sobre o meio ambiente, pois este é sujeito sócio-histórico-cultural, um ser da natureza e que, portanto, deve considerar-se parte da natureza, e ao considerar-se pertencente a ela, torna-se capaz de desenvolver a consciência ambiental (PENTEADO, 2001).

Em decorrência disto, o ambiente escolar deve estimular seus alunos a preservar o meio ambiente, visando sua sustentabilidade desde uma escala local até planetária. De acordo com Reigota (2001, p.37) "muitos são os métodos possíveis para a realização da Educação Ambiental", podendo ser estes métodos: passivo, no qual somente o professor ou mediador fala; ativo, fazendo trocas de experiências entre mediador e ouvintes; método descritivo, que visa aprender as definições da Educação Ambiental, analisando e registrando os fatores que se relacionam com os fenômenos ambientais; e, 
método analítico, segundo o qual os alunos podem completar a descrição dos fenômenos ambientais com dados e informações correspondentes.

É importante ressaltar que

as aulas expositivas do professor não são muito recomendadas na educação ambiental; mas elas podem ser muito importantes quando bem preparadas e quando deixam espaço para os questionamentos dos alunos. (...) a participação do cidadão na solução dos problemas deve empregar metodologias que permitam ao aluno questionar dados e ideias (...) (REIGOTA, 2001 p.37-38).

Desta forma, os métodos que proporcionam a integração de conhecimentos entre mediadores e ouvintes fazem com que sua fixação seja mais rápida e relevante.

Assim sendo,

na Educação Ambiental escolar deve-se enfatizar o estudo do meio ambiente onde vive o aluno, procurando levantar os principais problemas da comunidade, as contribuições da ciência, os conhecimentos necessários e as possibilidades concretas para a solução deles (REIGOTA, 2001 p.26-27).

Em face do exposto, a Educação Ambiental é um processo educativo de formação da cidadania, da consciência ambiental e capacidade de criar resoluções capazes de modificar o quadro ambiental da atualidade. A escola, portanto, é local imprescindível para se promover esta conscientização ambiental, sendo a sala de aula o espaço ideal para troca de experiências e conhecimentos, motivando os alunos a relatarem experiências vividas. E, para que haja esta relação entre professores e alunos, é preciso acompanhar as mudanças no contexto escolar, enfatizando as mudanças do contexto ambiental (REIGOTA, 2001).

Isto posto, as aulas de Geografia, têm papel de extrema importância no ensino da Educação Ambiental, pois as problemáticas ambientais afetam diretamente o objeto de estudo desta ciência, o espaço geográfico. Todavia, é necessário ressaltar que a Educação Ambiental não deve ficar somente sob a responsabilidade do professor de Geografia, uma vez que todas as disciplinas podem trabalhar esta temática no ambiente escolar (REIGOTA, 2001).

\section{A Educação Ambiental e a Geografia}

Desde seus primórdios a Geografia demostrou preocupação com as questões ambientais, pois essa ciência visa a relação entre sociedade/natureza. Os impactos ambientais são ocasionados pelas atitudes 
humanas sobre os espaços naturais. Assim sendo, surge a necessidade de formar cidadãos capazes de demostrar preocupações ambientalistas, buscando soluções capazes de modificar essas atitudes que prejudicam ou prejudicaram esses espaços, surgindo então a Educação Ambiental. Assim sendo, a Geografia é uma ciência que permite incentivar os alunos a observar, analisar e interpretar as realidades ambientais no contexto atual, fazendo ligações com a Educação Ambiental. O tema Educação Ambiental está cada vez mais presente nas formulações teóricas e indicações para o ensino da ciência geográfica, no sentido de formação de indivíduos para a vida no ambiente. Dessa forma, a temática contribui para com o processo de formação de uma consciência ambiental e conservacionista, não somente aos aspectos naturais, mas também no que se refere aos econômicos, sociais e culturais (CAVALCANTI, 1999).

A Educação Ambiental, segundo Rodriguez (2009) "[...] é um processo de aprendizagem e comunicação das questões relacionadas com a interação dos seres humanos com o ambiente, tanto em âmbito global, natural, como criado pelo homem" (RODRIGUEZ, 2009, p.175).

Desta forma, é possível considerar que as questões ambientais podem e devem estar inseridas na ciência geográfica, pois

a Geografia é, sem sombras de dúvidas, a única ciência que, desde a sua formação, se propôs ao estudo da relação entre os homens e o meio natural do planeta-meio ambiente, atualmente, em voga é propalado na perspectiva que engloba o meio natural e o social (MENDONÇA, 2004, p. 22-23).

A ciência geográfica é capaz de permitir abranger o estudo das relações existentes entre os homens e os espaços naturais, relações estas que são variáveis de acordo com as características de cada grupo humano, sendo estes capazes de transformar-se de acordo com suas necessidades e desejos.

Nesse sentido, é de fundamental importância que haja interação/articulação entre a ciência geográfica e a Educação ambiental, pois ambas estão correlacionadas às questões sociais, culturais e ambientais, com a relação entre homem/natureza. A articulação de ambas permite que os indivíduos tornem-se cada vez mais capazes de tomar decisões, solucionar problemas ambientais, permitindo assegurar uma qualidade de vida e uma qualidade ambiental a todos os indivíduos (REIGOTA, 2001). Para Cavalcanti (1999) "incluir o tema, vinculado a objetivos valorativos, visa permitir ao aluno trabalhar com suas diferentes concepções: o vivido, o percebido e o concebido" (CAVALCANTI, 1999, p. 124).

Assim sendo, esta articulação entre a Geografia e a Educação Ambiental permite que os indivíduos compreendam as relações que ocorrem nos meios naturais provocadas pelas ações humanas, sendo elas em sua maior parte prejudiciais a esses espaços, além de proporcionar a mentalidade de tomar os cuidados necessários com o meio ambiente, assegurando um 
ambiente de qualidade na atualidade e, principalmente, paras as futuras gerações de modo que a sociedade seja capaz de realizar ações que visam manter a qualidade ambiental e a vitalidade do Planeta Terra (MATOS; DANTAS, 2018).

De acordo com Boff (2012, p.14), ações essas que

(..) se destinam a manter a vitalidade e a integração da Mãe Terra, a preservação de seus ecossistemas com todos os elementos físicos, químicos e ecológicos que possibilitam a existência e a reprodução da vida, o atendimento das necessidades de presente e futuras gerações, e a continuidade da expansão e a realização das potencialidades da civilização humana em suas várias expressões.

A Geografia permite trabalhar ativamente as questões ambientais, as atitudes e ações para a preservação ambiental, juntamente com a Educação Ambiental. A nova Base Nacional Comum Curricular - BNCC de Geografia do Ensino Fundamental traz uma unidade temática que possibilita trabalhar a Educação Ambiental e as Questões Ambientais, sendo "Natureza, ambientes e qualidade de vida", buscando articular a Geografia física e Geografia humana, com o destaque para a discussão dos processos físico-naturais do planeta Terra (BRASIL, 2017).

Um exemplo desta articulação, a da ciência geográfica e da Educação Ambiental, pode ser analisada no trabalho realizado por Monteiro (2015), ao abordar as questões ambientais nas aulas de Geografia na turma de $7^{\circ}$ ano do ensino fundamental de uma escola municipal de Teresina (PI), no qual analisou resultados sobre a concepção de meio ambiente dos alunos. Verificou-se que o grau de entendimento dos alunos sobre as concepções ambientais em sua grande maioria é deficiente, ou seja, demonstrando que boa parte dos alunos não possui conhecimentos sobre a Educação Ambiental. Todavia, é importante ressaltar que uma pequena parcela dos alunos entrevistados, mesmo jovem, demostrou um grau de entendimento sobre as problemáticas ambientais da atualidade. Portanto, fica claro que as aulas de Geografia permitem trabalhar ativamente os conceitos ambientais e realizar a Educação Ambiental, pois a "superação de determinados problemas ambientais depende, além das alterações do modo de produzir da sociedade, de mudanças de comportamentos sociais e culturais, o que implica mudanças nas percepções ambientais do cidadão (CAVALCANTI, 1999, p. 124).

Nessa articulação da ciência geográfica junto a Educação Ambiental na sala de aula, busca-se trabalhar o lado racional dos indivíduos, estruturando-os juntamente com valores e atitudes capazes de ampliar o interesse e a capacidade, além do engajamento e autoconfiança na participação em promover benefícios socioambientais, gerando assim relações entre os conhecimentos científicos e práticas cotidianas nas relações ambientais (MARCATTO, 2002). 
Esta prática cotidiana sobre questões ambientalistas faz com que os indivíduos ajam eticamente com a própria civilização humana, além de ser ético com o meio natural, respeitando assim os seus limites (BOFF, 2004).

E em decorrência da necessidade de sensibilizar toda sociedade sobre as problemáticas ambientais, o ambiente escolar tem papel importantíssimo nesta difusão de conhecimentos, por ser facilitador no acesso a informações, além de proporcionar o ensino-aprendizagem através de práticas ambientais, despertando assim valores sociais, o senso de responsabilidade quanto às questões relacionadas com o meio ambiente, proporcionando, assim, que os alunos sejam capazes de ser sujeitos atuantes, no processo de modificação do quatro ambiental contemporâneo (OLIVEIRA; PEREIRA; JÚNIOR, 2018).

Para Leff (2009, p.222):

A sensibilização da sociedade, a incorporação do saber ambiental emergente no sistema educacional e a formação dos recursos humanos de alto nível foram considerados como processos fundamentais para orientar $e$ instrumentar as políticas ambientais.

Portando, observa-se a estreita ligação entre a ciência geográfica e a Educação Ambiental, ao permitir que transforme sujeitos leigos em indivíduos praticantes da conscientização ambiental, visando a qualidade ambiental de toda sociedade, das gerações presentes e, principalmente, das futuras. Se nada for feito neste momento histórico da civilização humana, as futuras gerações serão as prejudicadas com todos os problemas ambientais, tais como a perda permanente dos recursos naturais. O quadro atual socioambiental revela as problemáticas ambientais da sociedade, os impactos ocasionados pelas ações humanas, que cada vez se tornam mais complexas nos âmbitos quantitativos e qualitativos (JACOBI, 2003).

Desta forma, é necessário que se realizem práticas de ensino que abordem as questões ambientais. E nenhuma outra ciência trabalha uma grande variedade temas ambientais como a Geografia. Trabalhar práticas ambientais nas aulas de Geografia, proporcionando uma metodologia renovada não utilizando somente método expositivo, faz com que os alunos aprendam de forma conceitual através dos conhecimentos acadêmicos e de forma pontual com as práticas ambientais. A Educação Ambiental é um conhecimento em constante construção, desenvolvendo relações sobre as reflexões de interação homem/natureza. E a escola pode e deve ser palco do ensino da Educação Ambiental, fortalecendo uma prática educativa cada vez mais criativa e ampla (MATOS; DANTAS, 2018).

Dentro das múltiplas metodologias que podem ser aplicadas junto aos conhecimentos acadêmicos e científicos sobre a Educação Ambiental, a reciclagem de materiais sólidos é a mais comum, como ressalta Matos e Dantas (2018, p. 178):

revista brasileira educação ambiental 
O que mais se percebe nas práticas cotidianas, concernente ao meio ambiente, é uma supervalorização das diversas esferas sociais em transformar objetos como garrafas PET, pneus, tampas, entre outros, em materiais de decoração ou com outra finalidade (...).

É dentro desta percepção de um novo olhar da relação homem/natureza, que a ação de reciclar resíduos sólidos, que poderiam ser descartados de maneira incorreta, pode motivar a sensibilização da sociedade, promovendo mudanças necessárias (CÓRDULA; NASCIMENTO; LUCENA, 2018).

Diante disto, é importante que se realizem práticas sociais capazes de ser formadoras de uma consciência ambiental, haja vista que a degradação ambiental é configurada por práticas humanas que modificam os ecossistemas naturais de forma degradante e preocupante. Pois "a crise ambiental que o planeta vem passando é fruto da ação humana, na utilização da natureza" (CÓRDULA; NASCIMENTO; LUCENA, 2018, p.97).

As atividades educacionais correlacionadas às relações de uso consciente e sustentável dos recursos naturais e conservação do meio ambiente vem ganhado cada vez mais espaços nas salas de aula, pois as preocupações ambientais devem ser questões discutidas em todos os espaços (SPERANDIO; STIPP; STIPP, 2009).

Nesse sentido, as aulas de Geografia permitem realizar este questionamento, buscando posicionamentos dos alunos. E é no Ensino Médio da Educação Básica que se devem realizar de forma mais sistematizada e continua os questionamentos sobre as problemáticas ambientais, pois o público discente desse nível já tem maturidade para ser capaz de adquirir conhecimentos sobre os diversos problemas ambientais contemporâneos, buscando práticas para modificar este quadro, começando por mudanças individuas, ou seja, modificando o modo de agir de cada aluno sobre o meio ambiente. É na sala de aula o espaço ideal para se realizar o trabalho de desencadear conhecimentos, experiências e vivências sobre os diversos problemas ambientais, assim formando uma consciência cada vez mais vigorosa, alimentada e calcada no saber (PENTEADO, 2001).

Desta forma, as aulas de Geografia possibilitam cada vez mais o engajamento entre a aprendizagem educacional e o conhecimento das problemáticas ambientais contemporâneas, ocasionadas por atividades realizadas pela própria humanidade. Isso ocorre porque a nossa realidade ambiental é complexa, por isto necessita de um pensamento abrangente, capaz de compreender a complexidade deste momento histórico, construindo conhecimentos que levem indivíduos a criar soluções na mesma amplitude (MORAES, 2002). Portanto, a Educação Ambiental permite compreender as relações entre homem e natureza e os processos de mudanças antrópicas, que modificaram de formas preocupantes os espaços naturais e sociais. 


\section{Educação Ambiental nas aulas de Geografia do Ensino Médio: uma sequência didática}

A abordagem da Educação Ambiental nas aulas de Geografia ocorreu ao logo de duas semanas nas aulas de Geografia do Ensino Médio de uma escola da rede pública de Ensino localizada na cidade de Cornélio ProcópioPR, utilizando-se um total de doze aulas aplicadas nas turmas do $1^{\circ} \mathrm{A}$ e $1^{\circ} \mathrm{B}$, nas quais foram realizadas explicações por meio de aula expositiva, seguida do desenvolvimento de práticas de ensino envolvendo a reciclagem de resíduos sólidos e a confecção de artesanato.

A inclusão da Educação Ambiental no Currículo Escolar é de extrema importância, pois permite fomentar uma relação de harmonia no dinamismo da natureza com o homem, possibilitando por meio de novos conhecimentos valores e atitudes o processo de transformação do atual quadro ambiental do nosso planeta (GUIMARÃES, 2005). Correlacionar Educação Ambiental ao espaço escolar é trabalhar de forma consciente os aspectos sociais e ambientais tanto do passado, como do presente, e principalmente, do futuro. O professor assim como o aluno, sendo estes seres humanos acima de tudo, tanto seres individuais como sociais, têm o poder de assumir o papel de sujeito do processo de conscientização ambiental, relacionando desta forma o processo educativo junto ao contexto das relações sociais e ambientais (VEIGA, 1988).

As aulas foram divididas em dois momentos. $O$ primeiro momento utilizou-se de três aulas para cada turma, nas quais foram realizadas a explicação de conhecimentos relativos à Educação Ambiental e às principais conferências e encontros mundiais sobre o meio ambiente e a Educação Ambiental por meio do método de expositivo - com aula expositiva.

A aula expositiva tem por objetivos introduzir um novo assunto; permitir uma visão global de um assunto; esclarecer conceitos e concluir estudos (LOPES, 2001), sendo seu uso adequado para introduzir os alunos em tarefas de aprendizagem que terão prosseguimento com outro método e apresentar conceitos e princípios fundamentais que serão trabalhados no decorrer da unidade (RONCA, 1988). Segundo Lopes (2001) as vantagens da aula expositiva consistem na economia de tempo; supre a falta de bibliografia para o aluno; ajuda na compreensão de assuntos considerados complexos e estimula o pensamento criador do aluno.

Em um segundo momento, foram utilizadas novamente três aulas para cada turma, dedicadas ao desenvolvimento de práticas de ensino voltadas para trabalhar a Educação ambiental por meio da demonstração didática com a realização de oficinas com o intuito de formar a consciência ambiental dos alunos. As práticas abordaram especificamente a reciclagem de resíduos sólidos e a confecção de artesanato. A demonstração didática tem por objetivo proporcionar a articulação do conhecimento teórico com a prática, ilustrando o que foi exposto, discutido e lido em sala de aula, aprofundando assim 
conhecimentos, além de proporcionar alternativas capazes de propor soluções às problemáticas levantadas (VEIGA, 1988).

Reigota (2001) coloca que as metodologias pra trabalhar a Educação Ambiental devem permitir ao aluno questionar dados e ideias sobre um tema, propor soluções e apresentá-las, indicando entre os métodos, o ativo, que consiste em os alunos fazerem experiências sobre o tema.

As aulas práticas permitem que seja possível trabalhar conteúdos de base cientifica através de métodos e formas mais propícios para efetiva assimilação dos conteúdos por parte dos alunos (SAVIANI, 1985). Desta maneira, possibilitam que os alunos entendam melhor a situação da sociedade, os impactos ambientais ocasionados por atividades e atitudes humanas e as modificações dos espaços naturais, além de tornarem as aulas mais criativas e participativas. Consequentemente, as aulas práticas fazem com que os alunos se envolvam cada vez mais no processo educacional, na busca por soluções dos problemas ambientais, no uso consciente dos recursos naturais, além de tornarem os alunos sujeitos capazes de agir de forma ativa e positiva na modificação do quadro ambiental (CALLAl, 1999).

A realização de práticas ambientais faz com que a fixação dos conhecimentos da Educação Ambiental seja mais profunda e permanente, pois a Educação Ambiental deve permitir a formação da consciência ambiental, sendo ela um processo de construção da relação do homem com a natureza de maneira harmônica e consciente (TOZONI-REIS, 2003).

Foram realizadas quatro oficinas para trabalhar a Educação Ambiental, sendo elas: 1) Puff com caixa de leite (fig. 01); 2) Puff com pneu (fig. 02); 3) Artesanato com matérias recicláveis (fig. 03); e 4) Jardim suspenso com pallet, garrafa pet e pneu (fig. 04 e 05). Para tanto, a sala foi dividida em quatros grupos com sete pessoas, e cada equipe ficou responsável por uma oficina.

Para a construção do Puff de caixa de leite, foram utilizados os seguintes materiais: caixa de leite, jornais, fitas adesivas, tecido e pompom de lã. Compreendendo os seguintes passos, em um primeiro momento, houve a higienização das caixas, seguida do preenchimento das mesmas com folhas de jornal. O terceiro passo foi anexar uma caixa à outra com o uso de fita adesiva. O número total de caixas de leite foi de 24 unidades. Após a anexação das caixas de leite uma à outra, a estrutura foi encapada com tecido, seguida da fixação dos pompons de lã de diversas cores no assento. A equipe responsável pela oficina participou de forma ativa e, sempre que necessário, questionou quais passos deveriam ser seguidos e quais as formas para a sua melhor execução. O passo-a-passo e o resultado final podem ser visto na Figura 1. 


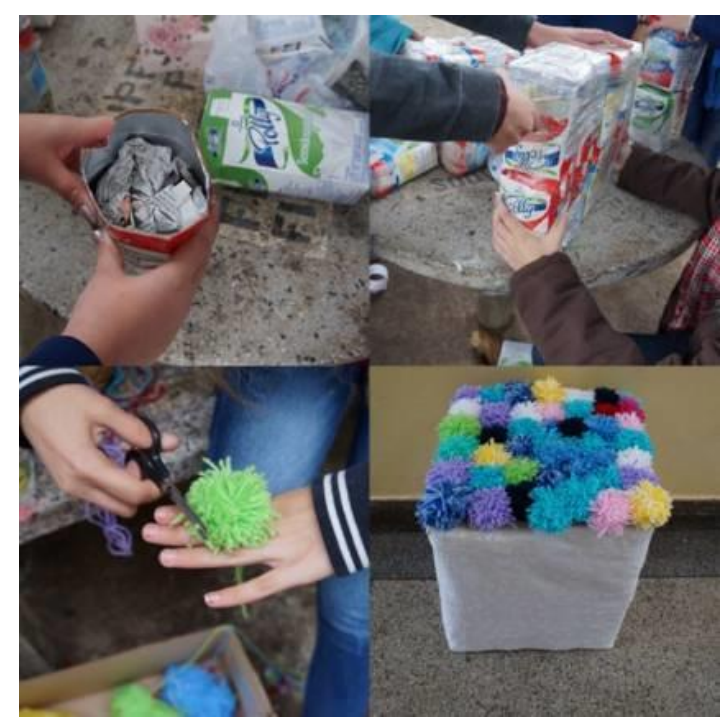

Figura 1: Confecção de caixa de leite com pompons de lã realizada por alunos do Ensino Médio de um Colégio Estadual da Cidade de Cornélio Procópio (PR), 2018.

Fonte: Oliveira (2018).

No processo de confecção do puff de pneu, foram utilizados os seguintes materiais: pneus, tampos de madeira, enchimento acrílico, tecidos, tintas, pinceis para pintura e furadeira. O primeiro passo foi realizar a limpeza dos pneus, seguindo com a pintura deles. Após a secagem, os pneus foram perfurados para fixação de um ao outro com o uso de furadeira e parafusos. $O$ terceiro passo foi envolver o tampo de madeira com a manta de enchimento, seguindo com a colocação do tecido. Assim, isso realizado foi necessário somente colocar o tampo sobre a circunferência do pneu, como pode ser visto na Figura 2. O grupo de alunos responsável pela confecção do puff de pneus interagiu de forma bastante satisfatória, sempre realizando questionamentos referentes ao passo-a-passo. Os alunos observaram que reutilizar pneus, além de trazer benefícios ambientais, possibilita transformar pneus em novos objetos que podem ser utilizados no dia a dia.

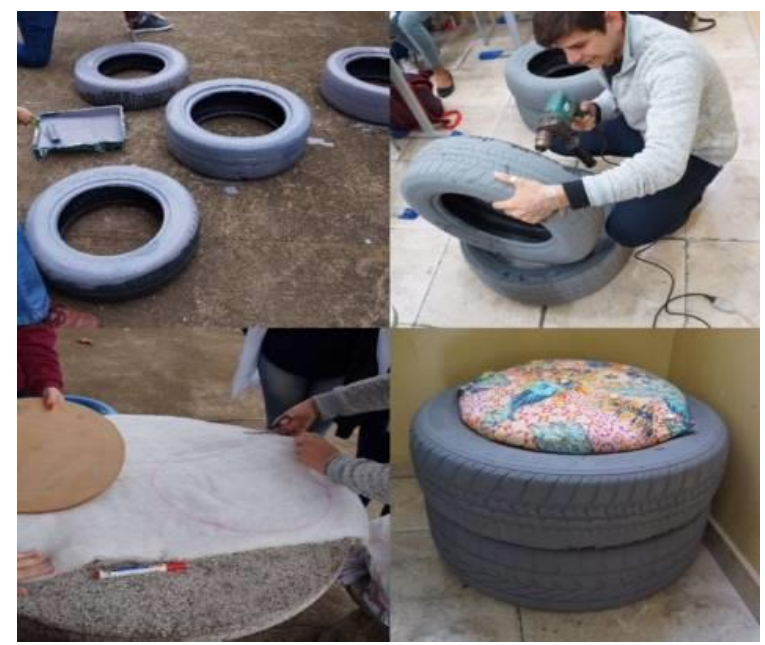

Figura 2: Puff feito com pneu, por alunos de um Colégio Estadual na Cidade de Cornélio Procópio (PR), 2018. Fonte: Oliveira (2018). 
Para realizar a oficina de criação de produtos artesanais, cujo tema principal foi festa de aniversário, a diversidade de materiais foi maior. Foram utilizados, latas de alumínio, cola branca, lápis, E.V.A, massa para biscuit, entre outros, como pode ser visto na Figura 3. Assim como nas demais práticas de reutilização de resíduos sólidos, nesta os alunos participantes se dedicaram e participaram com muito entusiasmo. Ambas as turmas tiveram a concepção dos benefícios ambientais que a reutilização de tais materiais pode trazer para o seu cotidiano. Além dos benefícios ambientais, os alunos compreenderam que a reutilização de resíduos sólidos, que muitas vezes são descartados de forma inadequada, traz consigo benefícios econômicos, com a diminuição dos custos para se criar objetos decorativos e lembranças para festas.

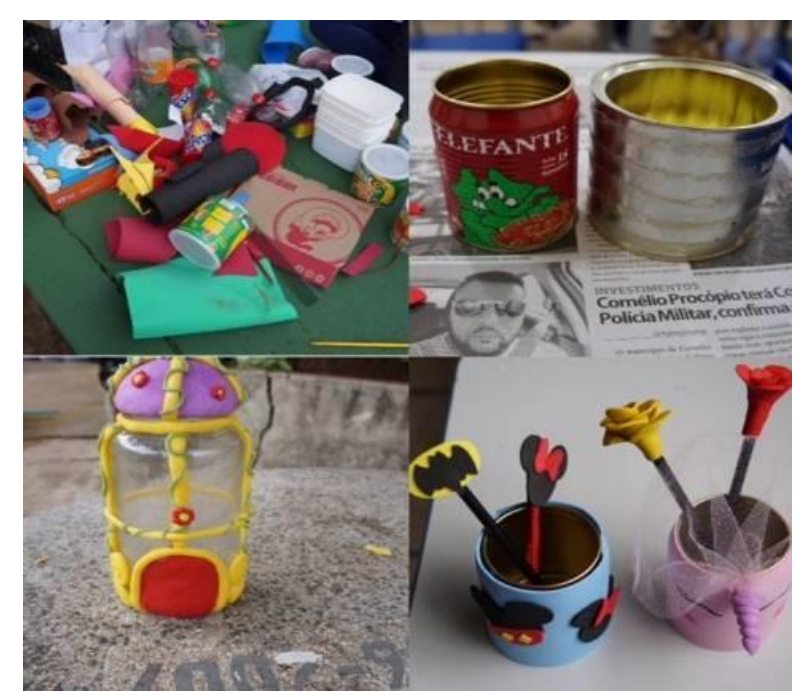

Figura 3: Artesanatos feitos com materiais reciclados, por alunos de um Colégio estadual da Cidade de Cornélio Procópio (PR), 2018. Fonte: Oliveira (2018).

A quarta prática ambiental foi a realização de um jardim suspenso, como pode ser visto nas Figuras 4 e 5 . Torna-se interessante ressaltar que a área de implantação do jardim estava sem uso e com alguns materiais jogados no local. Os materiais utilizados foram: pallet, garrafas pet, tinta, rolos para pintura, lixa para madeira, parafusos, furadeira, prego, martelo, terra vegetal e mudas de suculentas. Os alunos ficaram bastante atentos às explicações realizadas, sempre questionando quando haviam dúvidas quanto ao processo a ser realizado. Ambas as turmas se dedicaram na realização do jardim suspenso, se mostrando muito empolgados com o plantio das mudas. Desta forma, a realização do jardim suspenso, além de permitir a consolidação de práticas ambientais, possibilitou trazer vida e cor para uma área que antes estava praticamente abandonada. 


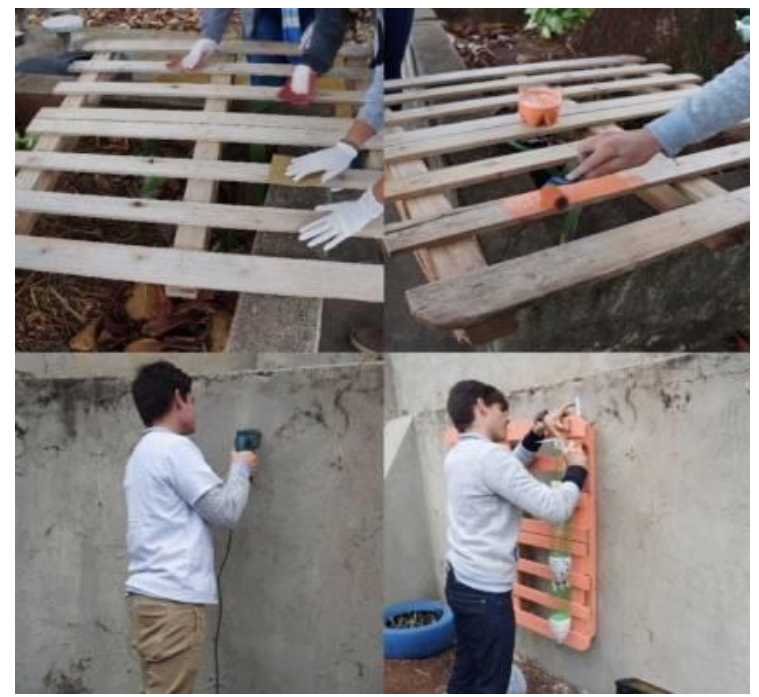

Figura 4: Processo de pintura e fixação do suporte do jardim suspenso em um Colégio Estadual da Cidade de Cornélio Procópio (PR), 2018. Fonte: Oliveira (2018).

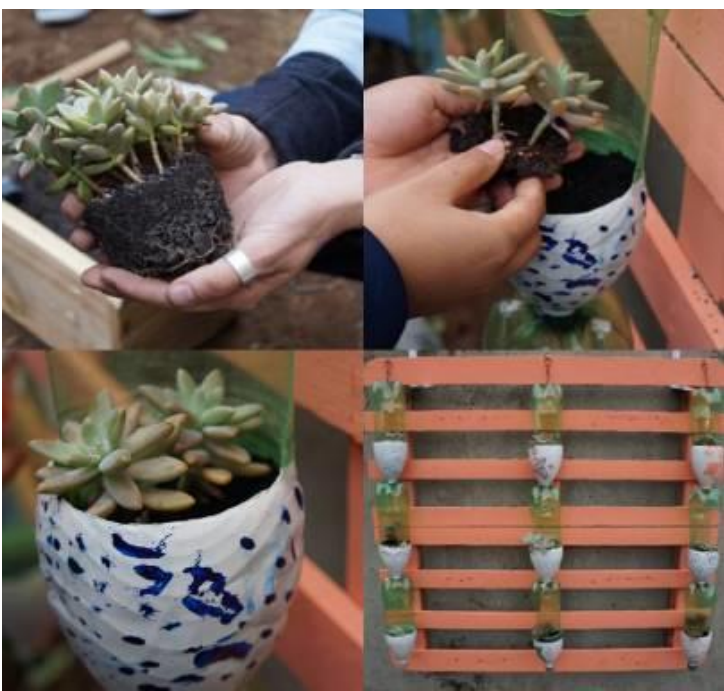

Figura 5: Jardim suspenso realizado por alunos de um Colégio Estadual da Cidade de Cornélio Procópio (PR), 2018.

Fonte: Oliveira (2018).

Com as práticas educacionais e ações em ensino-aprendizagem sobre Educação Ambiental, o processo de desenvolvimento da cidadania e da conscientização ambiental encontra nessas oportunidades possibilidade de concretização e fixação dos conteúdos, através de um ensino ativo e com participação dos alunos em sala de aula, sendo capaz de superar os impasses e problemas de insatisfação vividos em sala de aula, nos quais a transmissão de conhecimentos ficam alicerçados nos modos tradicionalistas, por meio de expositivíssimo somente realizado pelo professor (PENTEADO, 2001).

Neste sentido, a ciência geográfica, por ser a ciência que se dedica aos estudos relacionados à interação homem e natureza, faz com que o ensino de Educação Ambiental ganhe maiores engajamentos ao ser analisada através de conhecimentos científicos e acadêmicos, juntamente com as práticas de conscientização do consumo de recursos naturais, preservação e revitalização do meio ambiente, modificando assim o quadro de impactos ambientais. As aulas de Geografia proporcionam um leque de possibilidades de práticas ambientais, que visam trabalhar a coletividade, a participação ativa e, principalmente, a consciência ambiental, proporcionando aos alunos capacidades para observar os problemas ambientais e promover mudanças. $\mathrm{O}$ meio social está sobre o meio ambiente, sendo os dois inseparáveis, pois o homem no mesmo tempo que faz parte integrante da natureza é também um ser social, sendo detentor de conhecimentos e valores sociais, podendo assim atuar de forma continua sobre sua base natural (QUINTAS; OLIVEIRA, 1995).

Com efeito, o ensino de Educação Ambiental nas aulas de Geografia traz consigo esta finalidade: a de promover o conhecimento dos problemas ambientais que vem ocorrendo desde os primórdios da humanidade, mas que se intensificam cada vez mais, buscando despertar no aluno a consciência ambiental e o desejo de modificar esta realidade. Assim, a Educação Ambiental 
deve ser trabalhada de forma contínua, através de práticas de ensino que tornam as aulas mais prazerosas e ativas, promovendo melhorias na conscientização ambiental dos indivíduos.

Desta forma, ao se trabalhar a Educação Ambiental nas aulas de Geografia, por meio do método expositivo, junto com a demonstração didática e o desenvolvimento de práticas de ensino, foi possível perceber melhorias na compreensão dos alunos em relação à Educação Ambiental. Ao finalizarem o projeto, os alunos disseram que antes da realização das práticas, não haviam tido um contato mais aprofundado com a temática e, ao trabalhar a reciclagem de materiais e a confecção de artesanato, as práticas possibilitaram, além de entender o quadro de degradação ambiental planetário, apontar soluções para os problemas vivenciados no cotidiano.

Sabendo-se que o ensino de Educação Ambiental é indispensável na atualidade para alcançar resultados capazes de modificar a consciência ambiental dos indivíduos, faz-se necessário que esta temática seja abordada de maneira contínua e eficiente no ambiente escolar. E para tanto, é importante utilizar diferentes métodos de ensino, os quais não fiquem somente restritos ao expositivismo, sendo as práticas e oficinas um caminho metodológico viável no ensino de temáticas ambientais.

\section{Considerações Finais}

A Educação Ambiental consiste em tornar os alunos indivíduos ambientalmente conscientes, tendo real concepção das necessidades de transformar o atual quadro ambiental planetário, para que gerações futuras possam também usufruir dos recursos que hoje a sociedade humana consome. Neste sentido, justifica-se a permanência e a abordagem da Educação Ambiental no ambiente escolar e, principalmente, nas aulas de Geografia por ser esta uma disciplina que estuda a organização espacial e as derivações ambientais frutos da relação sociedade e natureza.

As práticas de Educação Ambiental apresentadas neste trabalho permitiram uma participação mais ativa dos alunos no processo de ensino e aprendizagem e melhor fixação dos conteúdos abordados, destacando que educar ambientalmente os alunos vai para além de se utilizar somente do processo educacional expositivo, sendo preciso utilizar metodologias diferenciadas, como as oficinas, que contextualizem os problemas ambientais vivenciados pelos alunos, utilizando-se de materiais de uso diário por parte dos mesmos.

Finalmente, para que haja melhorias da abordagem da Educação Ambiental nas aulas de Geografia, faz-se necessário que os professores sejam melhor capacitados para trabalhar a temática. Desta forma, recomenda-se que, junto à capacitação de professores na área de Educação Ambiental, sejam apontados outros métodos de ensino além do expositivo, destacando práticas de ensino que estimulem a participação ativa dos alunos e a formação da consciência ambiental tais como oficinas e laboratórios.

Revbea, São Paulo V. 14, № 1: 275-294, 2019. 


\section{Referências}

BARROS, J.D.S.; SILVA, M.F.P. Educação para a sustentabilidade ambiental e social em Cachoeira dos Índios - PB. REBAGA: Revista Brasileira de Educação Ambiental V. 3, №1, p. 38-44, 2009.

BOFF, L. Sustentabilidade: o que é, o que não é. Petrópolis, RJ: Vozes, 2012.

BOOF, L. Ecologia: Grito da Terra, Grito dos Pobres. Rio de Janeiro, Sextante, 2004.

BRASIL, MINISTÉRIO DA EDUCAÇÃO. Base Nacional Comum Curricular (BNCC). Brasília: MEC, 2017. Disponível em: http://basenacionalcomum. mec.gov.br/wp-content/uploads/2018/02/bncc-20dez-site.pdf. Acesso em: 17 jul. 2018.

BRASIL, Política Nacional de Educação Ambiental. Lei n 9.795/99, de 27 de abril de 1999. Disponível em: http://www.planalto.gov.br/ccivil 03/ Leis/19795.htm. Acesso em: 14 jun. 2018.

CALLAI, H.C. A Geografia no Ensino Médio. Revista TERRA LIVRE, São Paulo, № 14: 56-89, 1999.

CAVALCANTI, L.S. Proposta Curriculares de Geografia no Ensino: Algumas Referências de Análise. Revista TERRA LIVRE, São Paulo, № 14: 111-128, 1999.

CÓRDULA, E. B. L; NASCIMENTO, G.C.C; LUCENA, R.P.F. Comunidade, Meio Ambiente e Etnociência: Saberes Locais na Conservação dos Recursos Naturais. REVBEA: Revista Brasileira de Educação Ambiental, São Paulo, V. 13, № 2: 85-103, 2018.

DAMIANI, A. População e Geografia. 10ª Ed. São Paulo: Contexto, 2012.

DIAS, G. F. Educação Ambiental Princípios e Práticas. 6 ed. São Paulo: Gais Editora, 2000.

GUIMARÃES, M. A dimensão ambiental na educação. 6. Ed. Campinas: Papirus, 2005.

GUIMARÃES, M. Caminhos da Educação Ambiental: Da Forma à Ação. 4 ed. Campinas-SP: Papirus, 2010.

JACOBI, P. Educação Ambiental, Cidadania E Sustentabilidade. Caderno de Pesquisa, São Paulo, № 118: 189-205, 2003.

LEFF, E. Saber Ambiental: sustentabilidade, racionalidade, complexidade, poder. Tradução de Lúcia Mathilde Endlich Orth. 7. ed. Petrópolis: Vozes, 2009.

LOPES, A.O. Aula expositiva: superando o tradicional. In: VEIGA, I.P.A. Técnicas de ensino: Por que não?. 12. ${ }^{a}$ ed. São Paulo: Papirus, 2001. p.35-48

LOUREIRO, C.F.B. Educação Ambiental e Movimentos Sociais na Construção da Cidadania Ecológica e Planetária. In: LOUREIRO, C.F.B.; LAYRARGUES, P.P.; CASTRO, R.S. de (Org.). Educação Ambiental: repensando o espaço da cidadania. 2. Ed. São Paulo: Cortez, 2002. 
MARCATTO, C. Educação Ambiental: conceitos e princípios. 1 Ed. Belo Horizonte: FEAM, 2002.

MATOS, A.D.; DANTAS, M.C. Fragilidade do Ensino da Educação Ambiental: Viés da Customização. REVBEA: Revista Brasileira de Educação Ambiental, São Paulo, V.13, № 2: 170-185, 2018.

MENDONÇA, F. Geografia e Meio Ambiente. 7e., São Paulo: contexto, 2004.

MONTEIRO, G.L. Educação Ambiental no Ensino de Geografia: Uma Contribuição do PIBID Para Alunos do Ensino Fundamental. REVBEA: Revista Brasileira de Educação Ambiental, São Paulo, V. 10, № 1: 281-290, 2015.

MORAES, M.C. O Paradigma Educacional Emergente. São Paulo: Papirus, 2002.

NARCIZO, K.R.S. Uma análise sobre a importância de trabalhar educação ambiental nas escolas. Revista Eletrônica do Mestrado em Educação Ambiental, V. 22, jan./jul. 2009.

OLIVEIRA, F.R.; PEREIRA, E.R.; JÚNIOR, A.P. Horta Escolar, Educação Ambiental e a Interdisciplinaridade. REVBEA: Revista Brasileira de Educação Ambiental, São Paulo, V. 13, № 2: 10-31, 2018.

PENTEADO, H.D. Meio Ambiente e Formação de Professores. 4 ed. São Paulo: Cortez Editora, 2001. (Coleção Questões da Nossa Época; v.38).

QUINTAS, J.S.; OLIVEIRA, M.J.G. A Formação do Educador para Atuar no Processo de Gestão Ambiental. Brasília: IBAMA, 1995.

REIGOTA, M. O que é Educação Ambiental. São Paulo: Brasiliense, 2001. (Coleção primeiros passos; 292).

RODRIGUEZ, J.M. M; SILVA, E.V. Educação Ambiental e desenvolvimento Sustentável: problemática, tendência e desafios. Fortaleza: Ed. UFC, 2009.

SAVIANI, D. Sentido da Pedagogia e Papel do pedagogo. Revista da ANDE, São Paulo, № 9, p. 27 e 28, 1985.

RONCA, A.C.C.; ESCOBAR, V.F. Aula Expositiva. In.: RONCA, A.C.C.; ESCOBAR, V.F. Técnicas Pedagógicas: domesticação ou desafio a participação? Petrópolis: Vozes, 1988.

SPERANDIO, M.R.C.; STIPP, M.E.F.; STIPP, N.A.F. A Educação Ambiental no Parque Municipal Arthur Thomas. In: STIPP, N.A.F. (Org.). Análise Ambiental em Ciências da Terra. $1^{\underline{a}}$ ed. Londrina: Uel, V.2: 133-170, 2009.

TOZONI-REIS, M.E.C. Pesquisa em educação ambiental na universidade: produção de conhecimentos e ação educativa. In: TALAMONI, J.L.B.; SAMPAIO, A.C. (Org.). Educação Ambiental: da prática pedagógica à cidadania. São Paulo: Escrituras, p. 9-19. 2003.

VEIGA, I.P.A. Nos Laboratórios e oficinas escolares: a demonstração didática. In: RONCA, A.C.; ESCOBAR, V.F. Técnicas Pedagógicas: domesticação ou desafio a participação? Petrópolis: Vozes, 1998.

Revbea, São Paulo V. 14, № 1: 275-294, 2019. 